\title{
Early Helminth Infections Are Inversely Related to Anemia, Malnutrition, and Malaria and Are Not Associated with Inflammation in 6- to 23-Month-Old Zanzibari Children
}

\author{
Jacqueline K. Kung’u,* David Goodman, Hamad J. Haji, Mahdi Ramsan, Victoria J. Wright, \\ Quentin D. Bickle, James M. Tielsch, John G. Raynes, and Rebecca J. Stoltzfus \\ Cornell University, Division of Nutritional Sciences, Ithaca, New York; Johns Hopkins Bloomberg School of Public Health, Baltimore, Maryland; \\ Public Health Laboratory-Ivo de Carneri, Zanzibar, Tanzania; London School of Hygiene and Tropical Medicine, London, United Kingdom
}

Abstract. Helminths aggravate anemia and malnutrition among school children. We studied this association in a crosssectional study of 6- to 23-month-old Zanzibari children $(N=2322)$ and a sub-sample of 690 children matched on age and helminth infection status. Ascaris, hookworm, and Trichuris infections were diagnosed along with recent fever, malaria infection, mid-upper arm circumference (MUAC) and hemoglobin concentration (Hb). Alpha-1-acid glycoprotein (AGP), C-reactive protein (CRP), height, and weight were measured in the sub-sample. Infected children had higher $\mathrm{Hb}$ $(\beta=5.44 \mathrm{~g} / \mathrm{L}, P<0.001)$ and MUAC-for-age $\mathrm{Z}$ score $(\beta=0.30 \mathrm{Z}, P<0.001)$ compared with uninfected children after adjusting for covariates. Although helminths were not associated with inflammation, their association with Hb or MUAC-for-age $\mathrm{Z}$ score was modified by inflammation. Malaria-infected children were less likely to be infected with helminths (adjusted odds ratios 0.63 [95\% confidence interval: 0.49, 0.81]). Non-anemic, better nourished, or non-malaria-infected children may be more exploratory of their environments and therefore increase their exposure to soil-transmitted helminths.

\section{INTRODUCTION}

Geohelminths are widely prevalent, especially among the poorest communities of the developing world. ${ }^{1}$ The World Health Organization (WHO) estimates that over 2 billion people are infected and that $5-10 \%$ of these are children less than 24 months of age. ${ }^{2,3}$ Although only 300 million of those infected suffer severe or permanent impairment, a majority of the children suffer in a subtle and debilitating way. Helminth infections are known to aggravate malnutrition, anemia, and poor appetite,,, 5 and may retard both physical and cognitive development. ${ }^{6-8}$ Infection intensity increases with age and reaches a maximum between $5-14$ years. ${ }^{1,2}$ The impact of helminth infections in children less than 2 years of age has not been clearly defined, mainly because it has been assumed that these infections are rare or light and therefore not harmful.

Contrary to this assumption, young children experience first-time helminth infections, which might induce proinflammatory mediators that are detrimental to protein metabolism, appetite, and erythropoiesis. ${ }^{5,9-12}$ If so, incident helminth infections in this age group could contribute to anemia of inflammation. ${ }^{13-15}$ Helminth infections in endemic regions are typically associated with a highly polarized Th2 cytokine response, ${ }^{16,17}$ but these studies have been conducted in older children and adults. Measurement of inflammation in field studies that look at the relationship between helminth infection and different health outcomes has been rare. In addition, helminth-infected children may be more susceptible to other infections ${ }^{18,19}$ and consequently would bear the adverse effects of excess morbidity on malnutrition and anemia.

Contemporary studies looking at the relationship between helminth infections and different health outcomes present conflicting results ${ }^{8,20}$ and differential effects by age. ${ }^{5,21} \mathrm{~A}$ few intervention trials providing anthelmintic drugs to children less than 5 years of age have found no overall improvements in biochemical status and growth, ${ }^{22,23}$ in line with the notion that deworming benefits are seen only in children with heavier

*Address correspondence to Jacqueline K. Kung'u, Division of Nutritional Sciences, Cornell University, Savage Hall, Ithaca, NY 14853.E-mail: jm453@cornell.edu worm burdens, most of whom are school age. However, we previously reported that deworming benefited young Zanzibari children $\left(<30\right.$ months) with low worm burdens. ${ }^{5}$ Those in the treatment group (allocated $500 \mathrm{~g}$ mebendazole every 3 months) had 50\% lower incidence of severe anemia, 30-40\% less wasting malnutrition, and lower serum ferritin, an acute phase protein, than their placebo-treated peers. ${ }^{24}$ These findings advance the possibility that there may be an inflammatory or cytokine response pathway that is age dependent, and which operates in young children with light incident infections. ${ }^{24}$ Therefore, there is a need to quantify the magnitude of the relationship between early helminth infections and anemia or malnutrition in young children.

In this study, using a large sample size $(N=2,322)$ with rigorous helminth diagnosis, we test the following hypotheses: 1) early helminth infections are associated with anemia and malnutrition in 6- to 23-month-old Zanzibari children, 2) anemia and malnutrition are related to the presence of infection but not the worm burden, 3 ) the effects on anemia and malnutrition are mediated by the inflammatory or cytokine responses. The study was designed to replicate or refute the unexpected positive relationship that had been observed in $<30$-month-old children in Zanzibar, ${ }^{5}$ and to provide additional clarity on the mechanisms by which early helminth infections cause anemia and malnutrition.

\section{MATERIALS AND METHODS}

Study site. The study was carried out in Wete District of Pemba Island, Zanzibar, United Republic of Tanzania. Pemba is located in the Indian Ocean, approximately $50 \mathrm{~km}$ off the Tanzanian coast. It is mostly rural with only about $20 \%$ to $25 \%$ of its population (362,166 in 2002) living in town areas. In addition to subsistence agriculture and fishing the main economic activity is the clove industry, with more than $70 \%$ of Zanzibar's harvest being produced in Pemba. At the time of the study (2003-2004), Plasmodium falciparum malaria was highly prevalent ( $\sim 80 \%)$ with no distinct evidence of seasonality. ${ }^{25}$ The soil-transmitted helminths Ascaris lumbricoides, Trichuris trichiura, and hookworms (Ancylostoma duodenale and Necator americanus) are endemic. ${ }^{26}$ 
Study population and design. Beginning in July 2003, based on a house to house community census, 2,322 children aged 6-23 months were screened for helminth infections and were randomly allocated to mebendazole treatment (3-day course, $100 \mathrm{mg}$ twice a day) or identical placebo repeated every 3 months for a 12-month period. The results of the randomized trial will be published separately. Because of the low prevalence of early worm infections, to study inflammatory mechanisms, an immunology sub-sample was constructed at baseline that was enriched with infected children. The sub-sample consisted of 230 age-matched triplets (690 children) selected in a 2:1 ratio according to the infection status at baseline (two infected for one uninfected child). This work presents a cross-sectional analysis of the baseline group of children before randomized treatment was applied. To address hypotheses (1) and (2) we used data from the community-based sample and to address hypothesis (3) we use the sub-sample data.

The variables that were used in the community-based sample analyses included: hemoglobin concentration $(\mathrm{Hb})$ in $\mathrm{g} / \mathrm{L}$ $(N=2,175)$, Ascaris eggs per gram of feces $(N=2,124)$, hookworm eggs per gram of feces $(N=2,124)$, Trichuris eggs per gram of feces $(N=2,124)$, any helminth infection $(N=2,124)$, recent fever $(N=2,319)$, malaria infection $(N=2,076)$, and mid-upper arm circumference (MUAC)-for-age $\mathrm{Z}$ score $(N=2,322)$. Because of the small amount of plasma available for laboratory assays, the sub-sample was comprised of considerably fewer children, with $N=289$ for alpha-1-acid glycoprotein (AGP) $(\mathrm{g} / \mathrm{L})$ and $N=582$ for C-reactive protein (CRP) $(\mathrm{mg} / \mathrm{L})$. These sub-sample children for whom we have full biochemical results have similar characteristics to those with missing values for the analyses (data not shown).

Informed consent was obtained from the guardians of all enrolled infants. Ethical review committees of Johns Hopkins Bloomberg School of Public Health and Hygiene, Cornell University, London School of Hygiene and Tropical Medicine, and the Ministry of Health of Zanzibar reviewed and approved this research.

Assessments. For the larger community-based cohort of children, blood from a finger prick was collected into an EDTA capillary collection tube (Sarstedt, Nümbrecht, Germany), whereas for the children in the sub-sample, a venous sample of at least $3 \mathrm{~mL}$ was taken from the antecubital vein into a heparinized blood collection tube (Sarstedt), and a few drops taken from the butterfly needle tubing into an EDTA capillary collection tube (Sarstedt). Blood from the EDTA collection tube was used for the determination of $\mathrm{Hb}$ using a HemoCue hemoglobinometer (HemoCue, AB, Angelhom, Sweden), which was calibrated before use and also for the preparation of duplicate thick blood smears for assessment of malarial infection. The blood film was left to air dry and stained with $10 \%$ Giemsa and studied for malaria parasites by microscopy. Approximately 100 fields were scanned and the number of parasites were counted up to 200 leukocytes. If the number of parasites was 9 or less, parasites up to 500 leukocytes were counted. The number of parasites per microliter $(\mu \mathrm{L})$ was calculated by number of parasites $\times 8,000$ divided by the number of leukocytes counted, where 8,000 is the standard for the average number of leukocytes per $\mu \mathrm{L}$ and so allowed for a reasonable comparison between patients. Heparinized samples were spun at $1,300 \mathrm{rpm}$ for 5 minutes at $21^{\circ} \mathrm{C}$ and plasma aliquoted. Aliquots of plasma were stored at $-70^{\circ} \mathrm{C}$ and transported in dry ice to Cornell University and London School of Hygiene and Tropical Medicine (LSHTM) for analysis. Quantitative AGP was measured by radial immunodiffusion kits (Kent Laboratories, Bellingham, WA) and CRP was measured as previously described by Wright and Bickle, 2005. ${ }^{27}$

Ascaris, hookworm, and Trichuris infections were diagnosed by examination of three stool samples using Kato-Katz and sedimentation methods to maximize detection of light infections. Duplicate Kato-Katz slides were made from stool samples collected over 2 days. The preparation of slides was according to the WHO protocol. ${ }^{28}$ For samples that tested negative for Kato-Katz, a simple gravity sedimentation method was done as described by Goodman and others. ${ }^{29}$

Malnutrition was assessed by low MUAC-for-age Z score following the WHO standard protocol. ${ }^{30}$ The MUAC was the only growth indicator measured in the community-based sample. Height and weight were measured in the sub-sample and height for age $\mathrm{Z}$ score (HAZ), weight for height $\mathrm{Z}$ score (WHZ), and weight for age Z score (WAZ) calculated using EpiInfo software (CDC,Atlanta,GA) derived from age-specific reference data of the National Center for Health Statistics (NCHS)/WHO. ${ }^{30}$ Morbidity was assessed by 5-day maternal recall using local terms for fever, cough, and diarrhea.

Statistical analysis. We analyzed the data using SPSS software (version 16.0, SPSS, Inc., Chicago, IL). The association between early helminth infection and anemia or malnutrition was examined by using descriptive statistics, correlations, regression analysis and odds ratios. Data were assessed for normality by visual observation of distribution plots and Ascaris counts, hookworm counts, Trichuris counts, and CRP values were log-transformed to attain normality.

Frequencies, means and standard deviations, geometric means and $95 \%$ confidence interval (CI) were presented in subgroups defined by helminth infection intensities. Intensities of infection were calculated only for those infected using the following WHO classification ${ }^{31}$ :

\begin{tabular}{llll}
\hline \multicolumn{1}{c}{ Intensity } & \multicolumn{1}{c}{ Ascaris } & \multicolumn{1}{c}{ Hookworms } & \multicolumn{1}{c}{ Trichuris } \\
\hline Light & $1-4,999$ epg & $1-1,999$ epg & $1-999$ epg \\
Moderate & $5,000-49999$ epg & $2,000-3,999$ epg & $1,000-9,999$ epg \\
Heavy & $\geq 50,000$ epg & $\geq 4,000$ epg & $\geq 10,000$ epg \\
\hline
\end{tabular}

$P$ values based on analysis of variance (ANOVA) and Student's $t$ test statistics were used for comparing means. Pairwise comparisons between each pair of means were examined using post hoc Bonferroni test. The $\chi^{2}$ tests were used to compare proportions. The Pearson correlation coefficient $(r)$ was used to assess linear associations before multivariate analyses.

General linear models were used in regression analyses to explore the relationship between early helminth infections and anemia while controlling for covariates. A forward stepwise approach was used with variables kept in the final model if they had been previously identified as potential predictors, confounders, effect modifiers, or mediators from published literature and if they were significant at $P<0.10$.

Binary logistic regression was used to calculate the changes in the log odds of malaria, fever, anemia, and malnutrition in the community-based sample. Model $\chi^{2}$ were used to ensure goodness-of-fit. Adjusted odds ratios were used to interpret the odds of helminth infection associated with exposure to malaria, fever, anemia, and malnutrition. 


\section{RESULTS}

Distribution of early helminth infection, anemia, and malnutrition. In the community-based sample, about $25 \%$ of children were infected with one or more helminths and the majority of these had light worm burdens according to the WHO classification criteria. ${ }^{31}$ Trichuris infection was the most prevalent (16.6\%) followed by Ascaris (9.6\%) and hookworms $(3.6 \%)$ (Table 1). By design, two-thirds of the children in the sub-sample were infected, but among infected children, worm burdens were similar to those in the community-based sample (data not shown).

Contrary to expectation, the mean $\mathrm{Hb}$ was higher in the community-based cohort of children with helminth infection. Analysis by any helminth infection (i.e., combining all species of infection and categories of infection) showed significantly higher $\mathrm{Hb}$ in infected compared with non-infected children $(\Delta=7.7 \mathrm{~g} / \mathrm{L}, P<0.001)$. In contrast, similar analysis among children by recent fever (by maternal report) or malaria infection (by microscopy) showed significantly lower $\mathrm{Hb}$ in infected compared with their non-infected counterparts $(\Delta=-3.8 \mathrm{~g} / \mathrm{L}$ and $-8.5 \mathrm{~g} / \mathrm{L}$, respectively, $P<0.001$ ) (Figure $1 \mathrm{~A}$ ). However, when examined by category of infection intensity, the relationship of $\mathrm{Hb}$ to hookworm and Trichuris infection showed an inverse U-shape (Figure 1B). Among hookworm-infected children, the mean $\mathrm{Hb}$ of those with moderate infections $(N=2)$ was $7.8 \mathrm{~g} / \mathrm{L}$ less than that of those with light infections. Similarly, the mean $\mathrm{Hb}$ of children with heavy Trichuris infection $(N=2)$ was $15.5 \mathrm{~g} / \mathrm{L}$ less than that of those with moderate infections (Figure 1B). Although these mean differences are biologically significant, they are not statistically significant ( $P>0.999$ and $P=0.985$, respectively) because very few children were in these heavier categories of infection (Table 1).

Similarly, analysis of MUAC by any helminth infection showed significantly higher mean MUAC-for-age in infected children compared with non-infected $(\Delta=0.11 \mathrm{Z}, P=0.032)$. In contrast, children with recent fever or malaria infection had worse MUAC-for-age $\mathrm{z}$ scores compared with those without fever or malaria $(\Delta=-0.19 \mathrm{Z}$ and $-0.25 \mathrm{Z}$, respectively,

TABLE 1

Prevalence and intensity of helminth infection in the community-based sample*

\begin{tabular}{|c|c|c|c|c|}
\hline & \multicolumn{2}{|c|}{ Prevalence } & \multicolumn{2}{|c|}{ Intensity } \\
\hline & $\mathrm{n} /$ group & $\%$ & Mean $\stackrel{\leftarrow}{*}$ & $95 \%$ CI \\
\hline \multicolumn{5}{|l|}{$\overline{\text { Ascaris }}$} \\
\hline 0 & $1915 / 2119$ & 90.4 & 650.72 & $504.55-839.46$ \\
\hline $1-4,999$ & 178/2119 & 8.4 & & $(N=204)$ \\
\hline $5,000-49,999$ & 26/2119 & 1.2 & & \\
\hline \multicolumn{5}{|l|}{ Hookworms } \\
\hline 0 & $2046 / 2123$ & 96.4 & 106.78 & $68.77-165.81$ \\
\hline $1-1,999$ & $75 / 2123$ & 3.5 & & $(N=78)$ \\
\hline $2,000-3,999$ & $2 / 2123$ & 0.1 & & \\
\hline \multicolumn{5}{|l|}{ Trichuris } \\
\hline 0 & $1770 / 2122$ & 83.4 & 161.99 & $137.78-190.46$ \\
\hline $1-999$ & $320 / 2122$ & 15.1 & & $(N=354)$ \\
\hline $1,000-9,999$ & $30 / 2122$ & 1.4 & & \\
\hline$\geq 10,000$ & $2 / 2122$ & 0.1 & & \\
\hline \multicolumn{5}{|l|}{ Any helminth } \\
\hline No & $1629 / 2124$ & 76.7 & - & - \\
\hline Yes & $495 / 2124$ & 23.3 & & \\
\hline
\end{tabular}
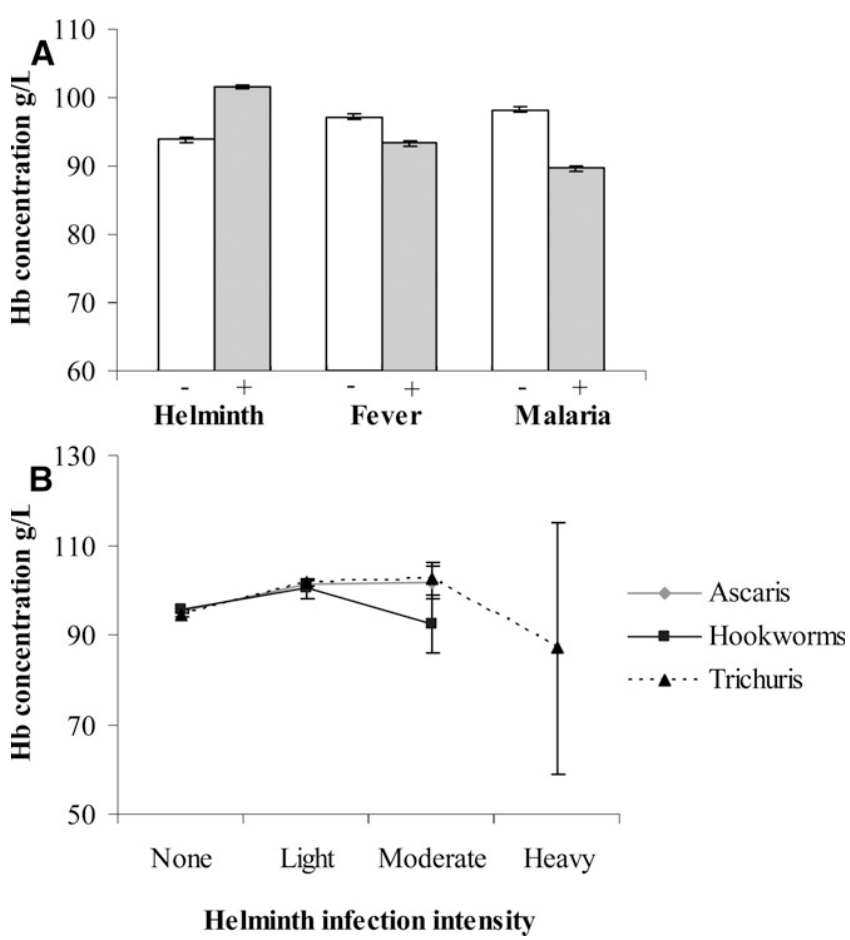

Figure 1. A, Relationship between hemoglobin concentration and infections in the community-based sample.* $\mathbf{B}$, Relationship between hemoglobin concentration and helminth infection intensity in the community-based sample. $\dagger+*$ Values are mean \pm SE $P$ value $<0.001$ for all comparisons, by $t$ test. $†$ The intensity of infection using WHO classification..$^{31}$ N's for each point in Table $1 . \ddagger$ Values are mean \pm SE with analysis of variance (ANOVA) $P$ value $<0.05$ comparing helminth infection intensity for each helminth.

$P<0.001)$ (Figure 2A). Similar analysis in the sub-sample children $(N=690)$ showed better attained growth in helminth-infected versus non-infected children in terms of HAZ $(\Delta=0.17 \mathrm{Z}, P=0.070)$ and WAZ $(\Delta=0.14 \mathrm{Z}, P=0.112)$, but not WHZ $(\Delta=-0.01 \mathrm{Z}, P=0.940)$, although none of these differences reached statistical significance.

MUAC-for-age Z score was low (mean \pm SD: $-0.93 \pm 0.97$ $\mathrm{Z})$ overall and was not statistically different by increasing helminth infection intensity $(P>0.05$, for each helminth species) (Figure 2B).

The role of inflammation. In general, increasing helminth infection intensities were not associated with the inflammation indicators (AGP and CRP) $(P>0.05$, for most comparisons) except that Trichuris-infected children had higher CRP values $(P=0.022)$. Notably, Trichuris-infected children with $\geq 10,000$ epg of feces had very high $\operatorname{AGP}(N=1,2.4 \mathrm{~g} / \mathrm{L})$ and $\operatorname{CRP}(N=2$, $33.45 \mathrm{mg} / \mathrm{L})$, although these observations were not statistically significant. Recent fever and malaria infection, however, were strongly associated with elevated inflammation indicators ( $P<0.05$, for all comparisons) (Table 2$)$. Increasing severity of anemia was associated with an increase in both AGP and CRP indicating a positive association between anemia and the acute phase response $($ APR $)(P$ value $<0.001)$ (Table 2$)$. Severity of wasting malnutrition was not significantly associated with higher inflammation indicators $(\mathrm{AGP} P$ value $=0.176$; $\mathrm{CRP}$ $P$ value $=0.325)($ Table 2$)$. Although the four children with MUAC-for-age Z score $<-3$ had CRPvalues above the accepted cutoff of $3 \mathrm{mg} / \mathrm{L}^{32}(4.09 \mathrm{mg} / \mathrm{L}, 5.20 \mathrm{mg} / \mathrm{L}, 10.28 \mathrm{mg} / \mathrm{L}$, and $47.93 \mathrm{mg} / \mathrm{L})$, the mean value (10.12 [\% CI: $1.74-58.98] \mathrm{mg} / \mathrm{L})$ 

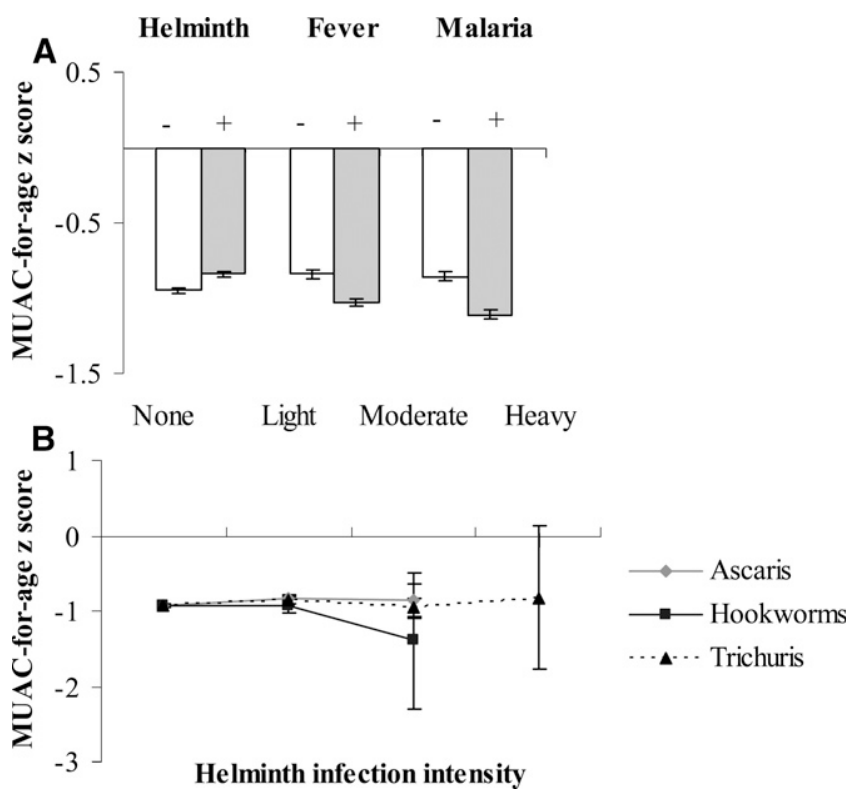

FIGURE 2. A, Relationship between mid-upper arm circumference (MUAC)-for-age Z score and infection indices in the community-based sample. ${ }^{*} \dagger \mathbf{B}$, Relationship between MUAC-for-age $\mathrm{Z}$ score and helminth infection intensity in the community-based sample. $\neq \S$ *Helminth infection is any infection (species combined) versus no infection. $†$ Values are mean \pm SE $P$ value $<0.001$ for recent fever and malaria infection, and $P=0.032$ for helminth infection, using $t$ test. $\$$ The intensity of infection using the WHO classification. ${ }^{31} \S$ Values are mean \pm SE with analysis of variance (ANOVA) $P$ value $>0.05$ comparing helminth infection intensity for each helminth.

was not significantly different from that of moderately malnourished or healthy children (Table 2).

We used Pearson correlations to examine further the strength of the linear relationships between variables. Again, Ascaris, hookworms, and Trichuris were found not to be significantly correlated with AGP or CRP (Table 3), but in this analysis, significant negative correlations were found for AGP and CRP with $\mathrm{Hb}$, MUAC-for-age $\mathrm{Z}$ score or HAZ $(P<0.05$ for all comparisons) (Table 3).

Is there a helminth anemia/malnutrition association after controlling for covariates? Finally, we examined whether the surprising associations between early helminth infections and anemia or wasting malnutrition persisted after controlling for covariates using multivariate and logistic regression models. Results from the community-based sample confirmed that helminth infection was positively associated with $\mathrm{Hb}(\beta=$ $5.44 \mathrm{~g} / \mathrm{L}, P<0.001)$ and MUAC-for-age $\mathrm{Z}$ score $(\beta=0.30 \mathrm{Z}$, $P<0.001)$ after adjusting for sex, age, malaria infection, and fever. However, these effects were modified by malaria (in the case of $\mathrm{Hb}$ ) and fever (in the case of MUAC-for-age Z score), such that the positive association between helminth infection and $\mathrm{Hb}$ (or MUAC-for-age Z score) was smaller in children who had malaria infection (or fever, in the case of MUAC-for-age $\mathrm{Z}$ score). Thus, for both $\mathrm{Hb}$ and MUAC, the "positive helminth association" was diminished by about $60 \%$ in the inflammatory condition of malaria infection or fever (Table 4A).

When the helminths were modeled singly, Trichuris infection had the largest positive effect on $\mathrm{Hb}(3.60 \mathrm{~g} / \mathrm{L}, P<0.001)$ and MUAC-for-age $\mathrm{Z}$ score $(0.19 \mathrm{Z}, P=0.002)$ after additionally adjusting for the effect of the other two helminths (data not shown).
We then explored the role of inflammation in the sub-sample where two specific markers of inflammation were measured: AGP and CRP. AGP was not retained in either the $\mathrm{Hb}$ or MUAC-for-age $\mathrm{Z}$ score model using a cutoff criterion of $P<0.10$ (Table 4B). As in the community-based sample, the association of helminth infection and $\mathrm{Hb}$ or MUAC-for-age $\mathrm{Z}$ score remained positive after adjusting for covariates, and this association was modified by inflammation. In the case of $\mathrm{Hb}$, the effect modification was strongest with $\mathrm{CRP}(\beta=-5.85 \mathrm{~g} / \mathrm{L}$, $P=0.045)$ and for MUAC-for-age $\mathrm{Z}$ score, with recent fever $(\beta=-0.34 \mathrm{Z}, P=0.044)$. In these models, the "positive helminth association" was completely absent in children with the inflammatory condition. The interaction is displayed graphically in Figure $3 \mathrm{~A}$ and $\mathrm{B}$.

We expected that early helminth infections would be associated with greater anemia and malnutrition and so these results were surprising. Given the cross-sectional nature of the analysis, we explored the possibility that the causal direction of the relationship was in the reverse, by using multivariate logistic regression analysis to estimate the risk of helminth infection associated with anemia or malnutrition (Table 5).

Helminth infection (defined as any species) was significantly less likely in anemic children (moderate anemia adjusted odds ratio [AOR]: $0.63,95 \% \mathrm{CI}: 0.50,0.80$; severe anemia AOR: 0.36, 95\% CI: 0.17, 0.75) and malnourished children (moderate malnutrition AOR: 0.66, 95\% CI: 0.45,0.96; severe malnutrition AOR: $0.53,95 \%$ CI: $0.18,1.59)$ after adjusting for age, sex, fever, and malaria infection, and also significantly less likely in malaria-infected children (malaria infection AOR: 0.63, 95\% CI: 0.49, 0.81) after adjusting for age, sex, and fever. When specific helminths were modeled separately, the pattern observed was consistent for Trichuris infection (the most common infection), with both anemia and wasting malnutrition being "protective" against infection in a dose-dependent manner. The pattern was less consistent with Ascaris and hookworms as outcomes. Anemia was "protective" against Ascaris, but severe acute malnutrition was not. For hookworm, the associations with severe anemia and wasting malnutrition were in the opposite direction. Although not statistically significant, children with severe anemia or moderate malnutrition were more likely to have hookworms and those with severe malnutrition were more likely to have Ascaris.

\section{DISCUSSION}

Helminth infections have adverse nutritional effects and their control can be achieved through regular inexpensive anthelminthic therapy. ${ }^{33}$ Traditionally, treatment efforts have been focused on school-age children because they have the highest worm burdens of any age group, and schools provide a cost-effective way to deliver anthelminthics. ${ }^{6}$ Justification for the inclusion of less than 24-month-old children in treatment is based on the hypothesis that important nutritional and health benefits could be obtained from regular deworming and from demonstrated safety of anthelmintic in this age group ${ }^{34}$ However, despite the recent proposal for inclusion of children 12 months and older in deworming programs, ${ }^{2,4}$ epidemiologic evidence to support this is scanty. This work aimed to increase the evidence by exploring the mechanisms through which early helminth infections may be associated with anemia or malnutrition in children 6-23 months of age. 
TABLE 2

The relationship between the acute phase response and helminths, reported recent fever, malaria infection, anemia, and malnutrition in the sub-sample*

\begin{tabular}{|c|c|c|c|c|c|c|}
\hline Infections & n/group & $\mathrm{AGP}(\mathrm{g} / \mathrm{L}) \dagger$ & $P$ value & n/group & $\mathrm{CRP}(\mathrm{mg} / \mathrm{L}) \ddagger \S$ & $P$ value \\
\hline \multicolumn{7}{|l|}{ Ascaris } \\
\hline 0 & $202 / 288$ & $1.58 \pm 0.70$ & \multirow[t]{3}{*}{0.743} & $390 / 550$ & $4.86(4.27,5.53)$ & \multirow[t]{3}{*}{0.157} \\
\hline $1-4,999$ & $74 / 288$ & $1.51 \pm 0.59$ & & $137 / 550$ & $3.85(3.06,4.83)$ & \\
\hline $5,000-49,999$ & $12 / 288$ & $1.55 \pm 0.38$ & & $23 / 550$ & $3.76(2.05,6.91)$ & \\
\hline \multicolumn{7}{|l|}{ Hookworms } \\
\hline 0 & $253 / 289$ & $1.57 \pm 0.66$ & \multirow[t]{3}{*}{0.934} & $492 / 554$ & $4.69(4.15,5.26)$ & \multirow[t]{3}{*}{0.405} \\
\hline $1-1,999$ & $36 / 289$ & $1.56 \pm 0.64$ & & $61 / 554$ & $3.92(2.94,5.23)$ & \\
\hline $2,000-3,999$ & - & - & & $1 / 554$ & 1.36 & \\
\hline \multicolumn{7}{|l|}{ Trichuris } \\
\hline 0 & $158 / 289$ & $1.61 \pm 0.70$ & \multirow[t]{4}{*}{0.316} & $265 / 553$ & $4.00(3.39,4.72)$ & \multirow[t]{4}{*}{0.022} \\
\hline $1-999$ & $118 / 289$ & $1.51 \pm 0.62$ & & $259 / 553$ & $5.18(4.44,6.04)$ & \\
\hline $1,000-9,999$ & $12 / 289$ & $1.46 \pm 0.48$ & & $27 / 553$ & $4.53(2.77,7.40)$ & \\
\hline$\geq 10,000$ & $1 / 289$ & 2.40 & & $2 / 553$ & $33.45(18.21,61.45)$ & \\
\hline \multicolumn{7}{|l|}{ Any helminth } \\
\hline No & $95 / 289$ & $1.64 \pm 0.76$ & \multirow[t]{2}{*}{0.184} & $154 / 555$ & $4.39(3.52,5.47)$ & \multirow[t]{2}{*}{0.665} \\
\hline Yes & $194 / 289$ & $1.53 \pm 0.60$ & & $401 / 555$ & $4.63(4.08,5.26)$ & \\
\hline \multicolumn{7}{|l|}{ Recent Fever } \\
\hline No & $165 / 289$ & $1.40 \pm 0.53$ & \multirow[t]{2}{*}{$<0.001$} & $319 / 559$ & $3.96(3.44,4.55)$ & \multirow{2}{*}{0.004} \\
\hline Yes & $124 / 289$ & $1.78 \pm 0.74$ & & $240 / 559$ & $5.45(4.58,6.47)$ & \\
\hline \multicolumn{7}{|l|}{ Malaria infection } \\
\hline No & $194 / 273$ & $1.41 \pm 0.59$ & \multirow[t]{2}{*}{$<0.001$} & $393 / 533$ & $3.54(3.13,4.01)$ & \multirow[t]{2}{*}{$<0.001$} \\
\hline Yes & $79 / 273$ & $1.94 \pm 0.69$ & & $140 / 533$ & $9.57(7.84,11.67)$ & \\
\hline \multicolumn{7}{|l|}{$\mathrm{Hb}$} \\
\hline$\geq 100$ & $158 / 284$ & $1.41 \pm 0.53$ & \multirow[t]{3}{*}{$<0.001$} & $311 / 551$ & $3.49(3.06,3.97)$ & \multirow[t]{3}{*}{$<0.001$} \\
\hline 70-99 & $110 / 284$ & $1.65 \pm 0.65$ & & $223 / 551$ & $5.86(4.88,7.05)$ & \\
\hline$<70$ & $16 / 284$ & $2.52 \pm 0.99$ & & $17 / 551$ & $17.43(8.55,35.52)$ & \\
\hline \multicolumn{7}{|c|}{ MUAC-for-Age Z } \\
\hline$\geq-2$ & $268 / 288$ & $1.55 \pm 0.64$ & \multirow[t]{3}{*}{0.176} & $514 / 558$ & $4.46(3.98,4.99)$ & \multirow[t]{3}{*}{0.325} \\
\hline$-2.01-3$ & $19 / 288$ & $1.83 \pm 0.89$ & & $40 / 558$ & $5.38(3.41,8.48)$ & \\
\hline$<-3$ & $1 / 288$ & 1.83 & & $4 / 558$ & $10.12(1.74,58.98)$ & \\
\hline
\end{tabular}

The positive association between early helminth infections and anemia or malnutrition. Our results that helminthinfected children without malaria infection, recent fever, or inflammation $(\mathrm{CRP}<3 \mathrm{mg} / \mathrm{L})$ have a better $\mathrm{Hb}$ and MUAC-

TABLE 3

Pearson correlation coefficients relating helminth egg counts, the APR, anemia, and malnutrition in the sub-sample*

\begin{tabular}{lccccc}
\hline & AGP $(\mathrm{g} / \mathrm{L})$ & $\mathrm{CRP} \dagger(\mathrm{mg} / \mathrm{L})$ & $\mathrm{Hb}(\mathrm{g} / \mathrm{L})$ & MUAC-for-age Z & $\mathrm{HAZ}$ \\
\hline Ascaris $\ddagger$ & & & & & \\
r & 0.049 & -0.004 & -0.002 & -0.103 & -0.097 \\
p & 0.655 & 0.959 & 0.974 & 0.159 & 0.183 \\
n & 86 & 160 & 187 & 188 & 188 \\
Hookworm $\ddagger$ & & & & & \\
r & -0.052 & -0.111 & 0.035 & -0.008 & -0.129 \\
p & 0.763 & 0.388 & 0.769 & 0.946 & 0.272 \\
n & 36 & 63 & 73 & 73 & 74 \\
Trichuris $\ddagger$ & & & & & \\
r & 0.118 & 0.096 & -0.118 & -0.033 & -0.006 \\
p & 0.180 & 0.104 & $\mathbf{0 . 0 3 4}$ & 0.552 & 0.912 \\
n & 131 & 290 & 326 & 327 & 327 \\
AGP(g/L) & & & & & \\
r & - & 0.627 & -0.332 & -0.148 & -0.168 \\
p & - & $<\mathbf{0 . 0 0 1}$ & $<\mathbf{0 . 0 0 1}$ & $\mathbf{0 . 0 1 2}$ & $\mathbf{0 . 0 0 4}$ \\
n & - & 262 & 284 & 288 & 289 \\
CRP $\dagger(\mathrm{mg} / \mathrm{L})$ & & & & & \\
r & - & - & -0.288 & -0.107 & -0.167 \\
p & - & - & $<\mathbf{0 . 0 0 1}$ & $\mathbf{0 . 0 1 2}$ & $<\mathbf{0 . 0 0 1}$ \\
n & - & - & 551 & 558 & 545 \\
\hline
\end{tabular}

*APR = acute phase response; $\mathrm{AGP}=$ alpha-1-acid glycoprotein; $\mathrm{Hb}=$ hemoglobin concentration; $\mathrm{CRP}=\mathrm{C}$-reactive protein; $\mathrm{MUAC}=$ mid-upper arm circumference; $\mathrm{HAZ}=$ height for age $\mathrm{Z}$ score.

$\dagger$ CRP was transformed to logarithm before analysis

\#Correlations were done with children with $>0$ epg feces. for-age $\mathrm{z}$ score than their non-infected counterparts were surprising, but actually reconfirm earlier findings of Stoltzfus and others ${ }^{21}$ in another cross-sectional analysis of 0 to 5 years of Zanzibari children. In that study, hookworm-infected children $<30$ months of age were found to have $4 \mathrm{~g} / \mathrm{L}$ higher average $\mathrm{Hb}$ values than children without infection. This is counterintuitive because helminth-induced nutritional impairment has been well documented in both animal and human studies. ${ }^{1}$ We speculate that this unexpected association is caused by greater exploratory behavior in healthier infants. ${ }^{21}$ Better nourished children will explore their environments more and therefore will be more exposed to the soil-transmitted helminths, whereas poorly nourished children are less exploratory and therefore limit their exposure to infective soil. Iron deficiency, iron deficiency anemia, stunting, or malaria have been found to significantly predict less locomotion in young Zanzibari children. ${ }^{35}$ It is important to note that the exploratory behavior hypothesis is likely to be more evident in these younger children who are just attaining the motor milestone than in school-age children, in whom helminth infections have been shown to predict anemia and malnutrition.

An alternative hypothesis is that helminths may find it more favorable to establish infection in a better-nourished child. It is becoming clearer that the interaction between parasites and nutrition can be considered from two standpoints; the better understood influence of the parasite on the host's physiology and nutrition and the less studied effect of host nutrition on parasite populations. Animal studies have provided information that the effect of host diet and nutrition may be important 
TABLE 4A

HB and MUAC-for-age $\mathrm{Z}$ score models used to analyze the associations in the community-based sample

\begin{tabular}{|c|c|c|c|c|}
\hline \multirow[b]{2}{*}{ Independent variable $\dagger$} & \multicolumn{2}{|c|}{$\mathrm{Hb}(\mathrm{g} / \mathrm{L})$ model $\$ \$ N=1877$} & \multicolumn{2}{|c|}{ MUAC-for-age $\mathrm{z}$ score Model $\mathbb{N} N=1896$} \\
\hline & $\beta(95 \% \mathrm{CI})$ & $P$ value & $\beta(95 \% \mathrm{CI})$ & $P$ value \\
\hline Intercept & $87.65(85.35,89.96)$ & $<0.001$ & $-0.39(-0.54,-0.24)$ & $<0.001$ \\
\hline Any helminth & $5.44(3.63,7.24)$ & $<0.001$ & $0.30(0.16,0.43)$ & $<0.001$ \\
\hline Sex (girl) & $1.53(0.24,2.82)$ & 0.020 & $0.12(0.03,0.20)$ & 0.008 \\
\hline Age (months) & $0.66(0.52,0.80)$ & $<0.001$ & $-0.04(-0.04,-0.03)$ & $<0.001$ \\
\hline Malaria infection & $-7.90(-9.51,-6.30)$ & $<0.001$ & $-0.19(-0.28,-0.10)$ & $<0.001$ \\
\hline Recent fever & $-2.60(-3.91,-1.29)$ & $<0.001$ & $-0.18(-0.28,-0.08)$ & $<0.001$ \\
\hline Any helminth*malaria infection & $-2.85(-6.24,0.54)$ & 0.099 & & \\
\hline Any helminth*recent fever & & & $-0.18(-0.38,0.02)$ & 0.075 \\
\hline
\end{tabular}

$\dagger$ Reference category $=$ no helminths, male child, no malaria, and no fever, respectively.

$\ddagger \mathrm{Hb}=\beta_{0}+\beta_{1}$ any helminth $+\beta_{2}$ sex $+\beta_{3}$ age $+\beta_{4}$ malaria infection $+\beta_{5}$ recent fever $+\beta_{6}$ any helminth*malaria infection, $\mathrm{R}$ squared $=0.156$

$\S$ No significant levels of variable*age interaction.

II MUAC-for-age $Z$ score $=\beta_{0}+\beta_{1}$ any helminth $+\beta_{2}$ sex $+\beta_{3}$ age $+\beta_{4}$ malaria infection $+\beta_{5}$ recent fever $+\beta_{5}$ any helminth*recent fever, $R$ squared $=0.059$.

in determining the overall helminth transmission success. ${ }^{36,37}$ For instance, helminths have been found to have specific physico-chemical requirements of their host gut environment, and nutritionally mediated changes have a direct influence on the parasite population. ${ }^{36}$ Similarly, iron supplementation in iron replete individuals has been associated with an increased risk of malaria. ${ }^{38,39}$

Finally, it is likely that the adverse effects of helminths take time to be evident in this nutritionally vulnerable age group. Our study targets young children who are just acquiring initial helminth infections and therefore the deleterious effects of the worms for child health may not yet be evident. Short exposure duration may be limiting the lack of expected helminth-induced effects in these young children. Thus, better nutritional status might be associated with early incidence of infection, but over time, the association could reverse as infection takes its nutritional toll. However, the nutritional toll of hookworms, which cause intestinal blood loss in amounts proportional to the number of adult worms in the gut, is likely to be evident immediately, although it may be apparent only above a certain worm burden threshold..$^{40}$

Ultimately, the causal direction of the relationship between helminths and anemia or malnutrition needs to be confirmed using a prospective experimental design. In the previous, smaller study, ${ }^{21}$ the cross-sectional relationship was similar to what we report here: helminth infection in young children (6-29 months) was associated with higher hemoglobin. And yet in the randomized trial that followed, anthelminthic treatment resulted in fewer cases of severe anemia. ${ }^{5}$ The data used in the present analysis study were baseline data for a larger randomized trial of children 6 to 24 months of age, the results of which will be published separately. However, based on the speculation that less severe anemia and malnutrition in children causes greater exposure to soil-transmitted helminths (rather than the reverse), and that longer duration of infection is associated with greater nutritional risk, anthelminthic treatment in this young age group might indeed prove beneficial.

The role of the acute phase response. If helminths were associated with malnutrition in young children, given the low worm burdens present, we hypothesized that helminth-induced inflammation might be the cause. ${ }^{21}$ We found no evidence of helminth-induced inflammation. The inflammatory response is characterized by a series of local and systemic effects that are collectively called the APR. ${ }^{41,42}$ This inflammatory response may result in production of proinflammatory cytokines such as IL-1, IL-6, and TNF- $\alpha$ that have been shown to be detrimental to nutrient metabolism, appetite, and erythropoiesis. ${ }^{11,12,43}$ To our knowledge, no prior studies have explored the role of helminth-induced inflammation in causing anemia among children less than 2 years of age.

Our data provide no evidence that helminths induce a proinflammatory response in contrast to malaria infection and recent fever. Further evidence for lack of association with helminths was that both CRP and alpha 1 anti-trypsin (A1AT) levels were unaffected by treatment (Raynes JG, personal communication). Additionally, malaria infection, severe anemia, and severe wasting malnutrition were positively associated with inflammation but inversely associated with helminths. This finding suggests that non-helminth-induced inflammation (possibly from malaria infection) modifies the positive helminth anemia/wasting malnutrition relationship. It is difficult to assign a temporal sequence in this predisposition

TABLE 4B

HB and MUAC-for-age Z score models used to analyze the associations in the sub-sample

\begin{tabular}{|c|c|c|c|c|}
\hline \multirow[b]{2}{*}{ Independent variable $\dagger$} & \multicolumn{2}{|c|}{$\mathrm{Hb}(\mathrm{g} / \mathrm{L})$ model $\$(N=522)$} & \multicolumn{2}{|c|}{ MUAC-for-age z score model $\$(N=552)$} \\
\hline & $\beta(95 \% \mathrm{CI})$ & $P$ value & $\beta(95 \% \mathrm{CI})$ & $P$ value \\
\hline Intercept & $93.07(86.93,99.20)$ & $<0.001$ & $-0.22(-0.56,0.13)$ & 0.214 \\
\hline Any helminth & $3.79(-0.50,8.07)$ & 0.083 & $0.34(0.12,0.56)$ & 0.002 \\
\hline Age (months) & $0.71(0.41,1.02)$ & $<0.001$ & $-0.04(-0.06,-0.02)$ & $<0.001$ \\
\hline Malaria infection & $-8.12(-11.16,-5.06)$ & $<0.001$ & - & - \\
\hline Recent fever & $-4.10(-6.68,-1.52)$ & 0.002 & $-0.03(-0.31,0.25)$ & 0.828 \\
\hline $\mathrm{CRP}>3 \mathrm{mg} / \mathrm{LI}$ & $-1.95(-6.93,3.04)$ & 0.443 & $-0.18(-0.33,-0.03)$ & 0.016 \\
\hline Any helminth*CRP $>3 \mathrm{mg} / \mathrm{Lg}$ & $-5.85(-11.58,-0.13)$ & 0.045 & - & - \\
\hline Any helminth*recent fever & - & - & $-0.34(-0.67,-0.01)$ & 0.044 \\
\hline
\end{tabular}

$\dagger$ Reference category $=$ no helminths, no malaria infection, no fever, CRP $\leq 3 \mathrm{mg} / \mathrm{L}$, respectively.

$\ddagger \mathrm{Hb}=\beta_{0}+\beta_{1}$ any helminth $+\beta_{2}$ age $+\beta_{3}$ malaria infection $+\beta_{4}$ recent fever $+\beta_{5} \mathrm{CRP}+\beta_{6}$ any helminth* CRP, $\mathrm{R}$ squared $=0.163$.

$\S$ MUAC-for-age Z score $=\beta_{0}+\beta_{1}$ helminth $+\beta_{2}$ age $+\beta_{3}$ recent fever $+\beta_{4}$ CRP $+\beta_{5}$ helminth*recent fever, R squared $=0.077$.

II CRP was transformed to logarithms before analysis. 
A

Community-based sample $(\mathrm{n}=\mathbf{1 8 7 7})$

$\square$ helminth negative $\square$ helminth positive

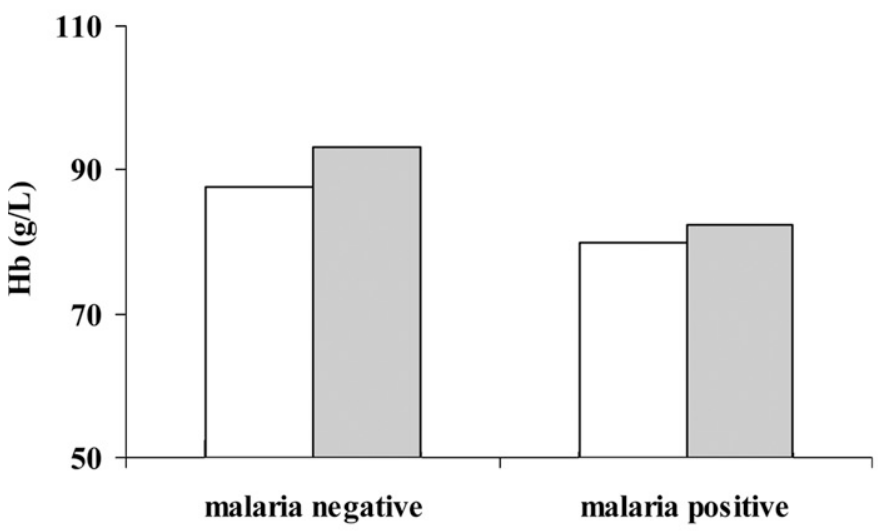

B

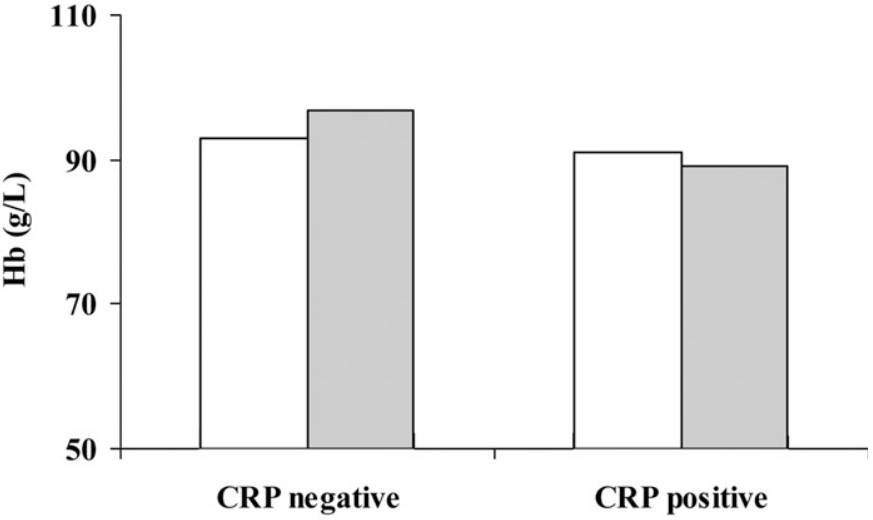

Sub-sample $(\mathrm{n}=\mathbf{5 5 2})$

$\square$ helminth negative $\square$ helminth positive

$\square$ helminth negative $\square$ helminth positive fever negative fever positive
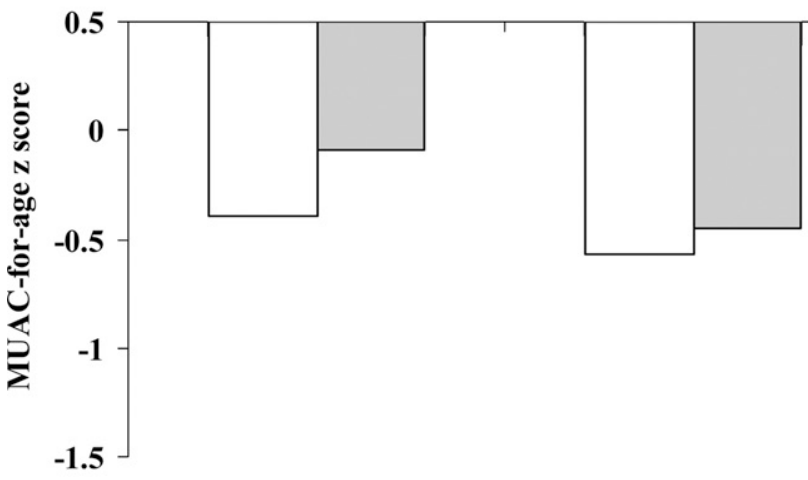

FIGURE 3. A, Relationship between hemoglobin concentration and helminth infection stratified by malaria infection in the community-based sample and C-reactive protein $(\mathrm{CRP})$ negative $(<3 \mathrm{mg} / \mathrm{L})$ or positive $(>3 \mathrm{mg} / \mathrm{L})$ in the sub-sample. B, Relationship between mid-upper arm circumference (MUAC)-for-age Z score and helminth infection stratified by recent fever in the community-based sample and sub-sample

caused by the cross-sectional nature of our analysis. The manuscript describing peripheral cytokine responses pre- and posttreatment is currently in submission.

There is similarly little evidence of helminth-induced inflammation in older children. C-reactive protein, a positive acute inflammatory marker, was found to be within normal limits before and after anthelminthic treatment in Indonesian children (8-11 years) chronically infected with Ascaris and Trichuris. ${ }^{44}$ However, two Bangladeshi studies among 8 to 11 year olds ${ }^{45}$ and among 2 to 5 year olds ${ }^{22}$ have found associations between plasma albumin concentration (a negative acute phase protein [APP]) and antichymotrypsin (a positive APP) and worm burdens, respectively, possibly indicating a low-grade systemic inflammatory response. ${ }^{15}$

TABLE 5

Association of helminth infections with anemia, malnutrition, and malaria infection in the community-based sample

\begin{tabular}{|c|c|c|c|c|c|c|c|c|c|c|c|c|}
\hline & \multicolumn{3}{|c|}{ Any helminth } & \multicolumn{3}{|c|}{ Ascaris } & \multicolumn{3}{|c|}{ Hookworms } & \multicolumn{3}{|c|}{ Trichuris } \\
\hline & $\mathrm{AOR}^{*}$ & $95 \% \mathrm{CI}$ & $P$ & AOR* & $95 \%$ CI & $P$ & $\mathrm{AOR}^{*}$ & $95 \%$ CI & $P$ & AOR* $^{*}$ & $95 \% \mathrm{CI}$ & $P$ \\
\hline \multicolumn{13}{|l|}{ Anemia } \\
\hline Moderate $(70-99 \mathrm{~g} / \mathrm{L}) \ddagger$ & $0.63(202)$ & $0.50-0.80$ & $<0.001$ & $0.65(85)$ & $0.47-0.90$ & 0.008 & $0.79(32)$ & $0.47-1.31$ & 0.355 & $0.70(145)$ & $0.53-0.91$ & 0.007 \\
\hline Severe $(<70 \mathrm{~g} / \mathrm{L}) \ddagger$ & $0.36(9)$ & $0.17-0.75$ & 0.006 & $0.57(6)$ & $0.23-1.37$ & 0.207 & $1.10(4)$ & $0.31-3.97$ & 0.882 & $0.26(4)$ & $0.09-0.73$ & 0.011 \\
\hline \multicolumn{13}{|l|}{ Malnutrition } \\
\hline Moderate $(<-2.01-3) \ddagger$ & $0.66(43)$ & $0.45-0.96$ & 0.028 & $0.83(21)$ & $0.50-1.37$ & 0.458 & $1.24(10)$ & $0.62-2.48$ & 0.544 & $0.67(30)$ & $0.43-1.03$ & 0.065 \\
\hline Severe $(<-3) \ddagger$ & $0.53(4)$ & $0.18-1.59$ & 0.256 & $1.09(3)$ & $0.32-3.69$ & 0.893 & $-(0)$ & - & - & $0.39(2)$ & $0.09-1.74$ & 0.217 \\
\hline Malaria infection $\dagger$ & 0.63 (119) & $0.49-0.81$ & $<0.001$ & $0.64(46)$ & $0.45-0.91$ & 0.012 & $0.72(19)$ & $0.42-1.22$ & 0.222 & $0.68(88)$ & $0.51-0.90$ & 0.007 \\
\hline
\end{tabular}


In conclusion, helminth-infected children were less anemic, less malnourished, and less likely to be malaria infected than uninfected children. We think the most likely explanation is that non-anemic, well-nourished, or non-malaria-infected children may be more motorically advanced or exploratory of their environments and therefore increase their exposure to soil-transmitted helminths. It is also possible that helminths may find it more favorable to establish infection in a betternourished child.

Received February 16, 2009. Accepted for publication July 7, 2009.

Acknowledgments: We thank the field and lab staff at the Public Health Laboratory-Ivo de Carneri for the field work and collection of blood and stool samples, and for sample aliquoting, the community of Pemba Island for their participation, Cornell University Human Metabolic Research Unit for generating the AGP data, and Joanna Szaub at the London School of Hygiene and Tropical Medicine for CRP data generation.

Financial support: This study was supported by a grant from the Wellcome Trust.

Authors' addresses: Jacqueline K. Kung'u and Rebecca J. Stoltzfus, Division of Nutritional Sciences, Cornell University, Savage Hall, Ithaca, NY 14853,Tel:607-379-3315, Fax:607-255-1033,E-mail:jm453@ cornell.edu. David Goodman and James M. Tielsch, Department of International Health, Johns Hopkins Bloomberg School of Public Health, 615 North Wolfe Street, Baltimore, MD 21205. Hamad J. Haji and Mahdi Ramsan, Pemba Public Health Laboratory, Ivo de Carneri, Box 122, Chake-Chake, Pemba Island, Zanzibar, The United Republic of Tanzania. Victoria J. Wright, Quentin D. Bickle, and John G. Raynes, Department of Infectious and Tropical Diseases, London School of Hygiene and Tropical Medicine, Keppel Street, London, United Kingdom WC1E 7HT.

\section{REFERENCES}

1. Crompton DW, Nesheim MC, 2002. Nutritional impact of intestinal helminthiasis during the human life cycle. Annu Rev Nutr 22: $35-59$.

2. WHO, 2005a. The Millenium Development Goals. The evidence is in: deworming helps meet the Millenium Development Goals. Geneva: World Health Organization.

3. WHO, 2002a. Report of the WHO. Informal Consultation on the Use of Praziquantel during Pregnancy/Lactation and Albendazole/Mebendazole in Children under 24 Months. Geneva: $W H O$

4. WHO, 2007. Action Against Worms. Deworming young children. Geneva: World Health Organization.

5. Stoltzfus RJ, Chway HM, Montresor A, Tielsch JM, Jape JK, Albonico M, Savioli L, 2004. Low dose daily iron supplementation improves iron status and appetite but not anemia, whereas quarterly anthelminthic treatment improves growth, appetite and anemia in Zanzibari preschool children. J Nutr 134: $348-356$.

6. WHO, 2002b. Prevention and Control of Schistosomiasis and Soiltransmitted Helminthiasis. Geneva: WHO.

7. Stoltzfus RJ, Kvalsvig JD, Chwaya HM, Montresor A, Albonico M, Tielsch JM, Savioli L, Pollitt E, 2001. Effects of iron supplementation and anthelmintic treatment on motor and language development of preschool children in Zanzibar: double blind, placebo controlled study. BMJ 323: 1389-1393.

8. Dickson R, Awasthi S, Williamson P, Demellweek C, Garner P, 2000. Effects of treatment for intestinal helminth infection on growth and cognitive performance in children: systematic review of randomised trials. BMJ 320: 1697-1701.

9. Ceciliani F, Giordano A, Spagnolo V, 2002. The systemic reaction during inflammation: the acute-phase proteins. Protein Pept Lett 9: 211-223.

10. Gabay C, Kushner I, 1999. Acute-phase proteins and other systemic responses to inflammation. $N$ Engl J Med 340: 448-454.

11. Plata-Salaman CR, 1998. Cytokine-induced anorexia. Behavioral, cellular, and molecular mechanisms. Ann N Y Acad Sci 856: 160-170.
12. Jelkmann W, 1998. Proinflammatory cytokines lowering erythropoietin production. J Interferon Cytokine Res 18: 555-559.

13. Weiss G, Goodnough LT, 2005. Anemia of chronic disease. N Engl J Med 352: 1011-1023.

14. Weiss G, 1999. Iron and anemia of chronic disease. Kidney Int Suppl 69: S12-S17.

15. Thurnham DL, Northrop-Clewes CA, 2007. Infection and the etiology of anemia. Kraemer K, Zimmermann MB, eds. Nutritional Anemia. Switzerland: Sight and Life Press, 231-256.

16. Cooper PJ, Chico ME, Sandoval C, Espinel I, Guevara A, Kennedy MW, Urban JF Jr, Griffin GE, Nutman TB, 2000. Human infection with Ascaris lumbricoides is associated with a polarized cytokine response. J Infect Dis 182: 1207-1213.

17. Negrao-Correa D, 2001. Importance of immunoglobulin $\mathrm{E}(\mathrm{IgE})$ in the protective mechanism against gastrointestinal nematode infection: looking at the intestinal mucosae. Rev Inst Med Trop Sao Paulo 43: 291-299.

18. Nacher M, Singhasivanon P, Yimsamran S, Manibunyong W, Thanyavanich N, Wuthisen R, Looareesuwan S, 2002. Intestinal helminth infections are associated with increased incidence of Plasmodium falciparum malaria in Thailand. J Parasitol 88: $55-58$.

19. Druilhe P, Tall A, Sokhna C, 2005. Worms can worsen malaria: towards a new means to roll back malaria? Trends Parasitol 21: 359-362.

20. Gulani A, Nagpal J, Osmond C, Sachdev HP, 2007. Effect of administration of intestinal anthelmintic drugs on haemoglobin: systematic review of randomized controlled trials. BMJ 334: 1095.

21. Stoltzfus RJ, Chwaya HM, Montresor A, Albonico M, Savioli L, Tielsch JM, 2000. Malaria, hookworms and recent fever are related to anemia and iron status indicators in 0- to 5-y old Zanzibari children and these relationships change with age. $J$ Nutr 130: 1724-1733.

22. Northrop-Clewes CA, Rousham EK, Mascie-Taylor CN, Lunn PG, 2001. Anthelmintic treatment of rural Bangladeshi children: effect on host physiology, growth, and biochemical status. Am J Clin Nutr 73: 53-60.

23. Dossa RA, Ategbo EA, de Koning FL, van Raaij JM, Hautvast JG, 2001. Impact of iron supplementation and deworming on growth performance in preschool Beninese children. Eur J Clin Nutr 55: 223-228.

24. Chwaya HM, Stoltzfus RJ, 2003. Helminth infections, growth, and anemia: lessons from Zanzibar. Crompton DWT, Montresor A, Nesheim MC, Savioli L, eds. Controlling Disease Due to Helminth Infections. Geneva: WHO, 33-42.

25. Mebrahtu T, Stoltzfus RJ, Chwaya HM, Jape JK, Savioli L, Montresor A, Albonico M, Tielsch JM, 2004. Low-dose daily iron supplementation for 12 months does not increase the prevalence of malarial infection or density of parasites in young Zanzibari children. J Nutr 134: 3037-3041.

26. Albonico M, Stoltzfus RJ, Savioli L, Tielsch JM, Chwaya HM, Ercole E, Cancrini G, 1998. Epidemiological evidence for a differential effect of hookworm species, Ancylostoma duodenale or Necator americanus, on iron status of children. Int J Epidemiol 27: $530-537$

27. Wright V, Bickle Q, 2005. Immune responses following experimental human hookworm infection. Clin Exp Immunol 142: 398-403.

28. WHO, 1991. Basic Laboratory Methods in Medical Parasitology. Geneva: World Health Organization.

29. Goodman D, Haji HJ, Bickle QD, Stoltzfus RJ, Tielsch JM, Ramsan M, Savioli L, Albonico M, 2007. A comparison of methods for detecting the eggs of Ascaris, Trichuris, and hookworm in infant stool, and the epidemiology of infection in Zanzibari infants. Am J Trop Med Hyg 76: 725-731.

30. WHO, 1995. Physical status: the use and interpretation of anthropometry. WHO Technical Report Series No. 854. Geneva:World Health Organization.

31. Montresor A, Crompton DWT, Hall A, Bundy DAP, Savioli L, 1998. Guidelines for the Evaluation of Soil-transmitted Helminthiasis and Schistosomiasis at Community Level. WHO document WHO/CTD/SIP/98.1. Geneva: World Health Organization.

32. Beard JL, Murray-Kolb LE, Rosales FJ, Solomons NW, Angelilli ML, 2006. Interpretation of serum ferritin concentrations as indicators of total-body iron stores in survey populations: the 
role of biomarkers for the acute phase response. Am J Clin Nutr 84: 1498-1505.

33. WHO, 2005b. Deworming for Health and Development. Report of the third global meeting of the partners for parasite control. Geneva: World Health Organization.

34. Montresor A, Stoltzfus RJ, Albonico M, Tielsch JM, Rice AL, Chwaya HM, Savioli L, 2002. Is the exclusion of children under 24 months from anthelmintic treatment justifiable? Trans $R$ Soc Trop Med Hyg 96: 197-199.

35. Olney DK, Pollitt E, Kariger PK, Khalfan SS, Ali NS, Tielsch JM, Sazawal S, Black R, Mast D, Allen LH, Stoltzfus RJ, 2007. Young Zanzibari children with iron deficiency, iron deficiency anemia, stunting, or malaria have lower motor activity scores and spend less time in locomotion. J Nutr 137: 2756-2762.

36. Petkevičius S, 2007. The interaction between intestinal helminth infection and host nutrition. Veterinarija Ir Zootechnika 37: $53-60$.

37. Held MR, Bungiro RD, Harrison LM, Hamza I, Cappello M, 2006. Dietary iron content mediates hookworm pathogenesis in vivo. Infect Immun 74: 289-295.

38. Shankar AH, 2000. Nutritional modulation of malaria morbidity and mortality. J Infect Dis 182 (Suppl 1): S37-S53.

39. Sazawal S, Black RE, Ramsan M, Chwaya HM, Stoltzfus RJ, Dutta A, Dhingra U, Kabole I, Deb S, Othman MK, Kabole FM, 2006. Effects of routine prophylactic supplementation with iron and folic acid on admission to hospital and mortality in preschool children in a high malaria transmission setting: communitybased, randomised, placebo-controlled trial. Lancet 367: 133-143.

40. Stoltzfus RJ, Albonico M, Chwaya HM, Savioli L, Tielsch J, Schulze K, Yip R, 1996. Hemoquant determination of hookwormrelated blood loss and its role in iron deficiency in African children. Am J Trop Med Hyg 55: 399-404.

41. Tomkins A, 2003. Assessing micronutrient status in the presence of inflammation. $J$ Nutr 133: 1649S-1655S.

42. Wieringa FT, Dijkhuizen MA, West CE, Northrop-Clewes CA, Muhilal, 2002. Estimation of the effect of the acute phase response on indicators of micronutrient status in Indonesian infants. J Nutr 132: 3061-3066.

43. Grimble RF, 1989. Cytokines: their relevance to nutrition. Eur J Clin Nutr 43: 217-230.

44. Karyadi E, Gross R, Sastroamidjojo S, Dillon D, Richards AL, Sutanto I, 1996. Anthelminthic treatment raises plasma iron levels but does not decrease the acute-phase response in Jakarta school children. Southeast Asian J Trop Med Public Health 27: 742-753.

45. Northrop CA, Lunn PG, Wainwright M, Evans J, 1987. Plasma albumin concentrations and intestinal permeability in Bangladeshi children infected with Ascaris lumbricoides. Trans $R$ Soc Trop Med Hyg 81: 811-815. 